\title{
FATIGUE PERFORMANCE OF EPOXY-BASED CONCRETE FOR BRIDGE EXPANSION JOINT RAPID REPAIR AND THE REPAIRED CONCRETE MEMBERS
}

\author{
WEI CHEN*, YUANBIAO ZHENG**, CHUANHUI TANG***, WEIJIE ZHUGE*, "YIDONG XU*,*** \\ *School of Civil Engineering and Architecture, NingboTech University, Ningbo 315100, China \\ **Ningbo Communications Planning Institute Co., Ltd, Ningbo 315192, China \\ ***School of Civil Engineering, Chongqing Jiaotong University, Chongqing 400074, China \\ "E-mail: xyd@nbt.edu.cn
}

Submitted July 21, 2021; accepted September 10, 2021

\begin{abstract}
Keywords: Epoxy-based concrete, Rapid repair, Fatigue life, Stress-strain curve, Energy consumption
In this paper, a new epoxy-based concrete for bridge expansion joint rapid repair (EJR) has been prepared, and the fatigue performance of the EJR and the repaired concrete members are investigated. The results show that the EJR has excellent fatigue performance compared with cement-based materials for rapid repair. There is no interface transition zone in the EJR, which means that the EJR has fewer internal defects. Based on an analysis of the stress-strain curve and energy consumption, the fatigue life equation of the EJR and repaired concrete members is established, which are suitable for the semilogarithmic form and the correlation coefficients of the linear fit are above 0.95. The investigation provides a reference for predicting the fatigue life of a repaired bridge expansion joint.
\end{abstract}

\section{INTRODUCTION}

With the rapid development of the transportation industry, China's road and bridge construction has achieved remarkable advancements. However, the increased traffic volume and various unfavourable environmental factors have caused the premature destruction of road surfaces.

Epoxy-based concrete has the advantages of a high initial strength, low shrinkage, excellent water resistance, and robust ultimate deformation ability $[1,2]$. EJR, as a new type of epoxy-based material, is suitable for pavement or bridge expansion joint rapid repair and has broad application prospects in improving the structural bearing capacity and durability [3-5].

For a repaired pavement, due to the difference between the elastic modulus of the repair materials and pavement concrete, the bond surface will produce greater stress and deformation under the repeated action of vehicle loading. Therefore, the fatigue performance of the bond surface must be investigated.

At present, research on the fatigue performance of epoxy-based concrete usually adopts the fatigue analysis method of asphalt mixtures, and the strain control mode is used in fatigue tests $[6,7]$. However, since the fatigue failure criterion of epoxy-based concrete is not specified, the established fatigue life equation has certain limitations. The aim of this paper is to investigate the fatigue performance of EJR and the repaired concrete members, and provide a reference for predicting the fatigue life of the repaired bridge expansion joint. In this study, the stress analysis method is adopted, and the complete fracture of a specimen is adopted as the fatigue failure criterion. Combined with the existing fatigue models of cement concrete and asphalt mixtures, the fatigue performance of the EJR and repaired concrete members is analysed, and a corresponding fatigue life equation is established based on the fatigue testing data, thus providing guidance for actual engineering repairs.

\section{EXPERIMENTAL}

Fatigue analysis method

Figure 1 shows the compressive stress-strain curve of EJR. During the a-b stage, the stress-strain curve initially changes elastically. As the stress increases, the plastic deformation accelerates, which means that the internal micro-cracks of the specimen are compressed and closed. During the b-c stage, the stiffness of the specimen increases rapidly. After the stress of specimen exceeds the peak point $d$, the bearing capacity of the specimen is provided by the frictional resistance on the shear surface and the residual cohesive force, and thus the bearing capacity begins to decrease steadily. As a new type of epoxybased material, EJR has a ductile deformation capacity close to that of asphalt mixtures, but its compressive stress-strain curve is similar to that of cement concrete. 


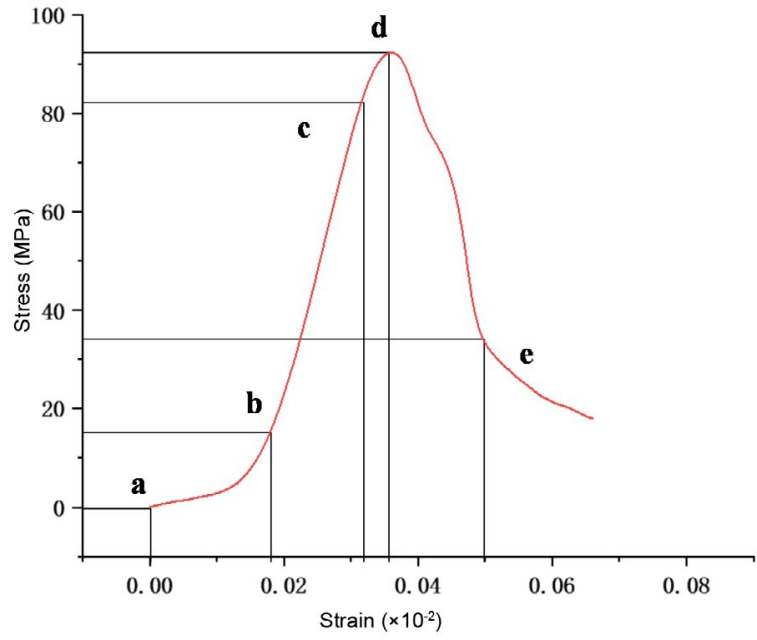

Figure 1. Compressive stress-strain curve of the EJR.

Based on the above analysis, the authors combined the fatigue model of cement concrete and asphalt mixtures to analyse the fatigue performance of EJR and the repaired concrete members. The fatigue analysis methods used are phenomenological methods and energy methods [8]. When applying the phenomenological methods to fatigue tests, two different loading modes can be used: stress control or strain control $[9,10]$. In the strain control mode, the criterion of fatigue failure reduces the stiffness modulus of the asphalt mixture to $50 \%$ or less. Since the compressive stress-strain curve of EJR is similar to that of cement concrete, as shown in Figure 1, it is difficult to define the corresponding stiffness modulus. When adopting the strain control mode for fatigue testing, it is difficult to define the corresponding fatigue failure criterion. Therefore, the stress control mode $[11,12]$ is adopted in this fatigue test, and the complete fracture of the specimen is taken as the fatigue failure criterion. The energy method is used to analyse the fatigue performance of materials from the view of the energy consumption. The specimen cannot completely return to its original state after each cyclic load, and its interior will change slightly. Therefore, each loading cycle will cause slight damage to the interior of the specimen, and with an increase in the number of cycles, the damage will gradually accumulate until the specimen fails [1315]. The whole process is essentially a process of energy consumption, so the dissipated energy can be used to analyse the damage to the materials and then study their fatigue behaviour $[16,17]$.

\section{Materials}

Aggregates: The properties of the aggregate meet the Chinese Standard CJJ1-2008 "Code for construction and quality acceptance of road works in a city and town", as shown in Table 1.

Mineral powder: Alkaline limestone mineral powder. The related properties are shown in Table 2.

Binder: The type NPEL128(E51) epoxy composed of two $\mathrm{a} / \mathrm{b}$ components, which was produced by Ningbo Tianyi Steel Deck Pavement Technology Co., Ltd., was used.

Concrete specimens for the rapid repair (damaged concrete): A total of nine concrete specimens were prepared. The designed concrete compressive strength is $30 \mathrm{MPa}$, and the size is $100 \times 100 \times 400 \mathrm{~mm}$. After 28 days of standard curing, the specimens were broken and used for the preparation of the repaired concrete members.

EJR: The mix proportions of the EJR are shown in Table 3. The ratio of the $\mathrm{a} / \mathrm{b}$ component in epoxy is $2: 1$. A total of 19 EJR specimens with a size of $100 \times 100 \times$ $400 \mathrm{~mm}$ were prepared.

Table 2. Properties of the mineral powder

\begin{tabular}{lccc}
\hline \multicolumn{1}{c}{ Properties } & Measured value & Requirement \\
\hline Apparent relative density & 2.62 & $\geq 2.5$ \\
Moisture content (\%) & 0.5 & $\leq 1$ \\
& $<0.600 \mathrm{~mm}$ & 100 & 100 \\
Particle size (\%) & $<0.150 \mathrm{~mm}$ & 95 & $90 \sim 100$ \\
& $<0.075 \mathrm{~mm}$ & 85.3 & $75 \sim 100$ \\
\hline
\end{tabular}

Table 1. Properties of the aggregate.

\begin{tabular}{ccccc}
\hline $\begin{array}{l}\text { Size } \\
(\mathrm{mm})\end{array}$ & $\begin{array}{c}\text { Apparent } \\
\text { relative density }\end{array}$ & $\begin{array}{c}\text { Water absorption } \\
(\%)\end{array}$ & $\begin{array}{c}\text { Crush value } \\
(\%)\end{array}$ & $\begin{array}{c}\text { Needle flake } \\
\text { content }(\%)\end{array}$ \\
\hline $0 \sim 3$ & 3.165 & 1.81 & - & 4.1 \\
$3 \sim 5$ & 2.916 & 1.46 & 9.6 & 3.8 \\
$5 \sim 10$ & 2.919 & 0.38 & 10.8 & 5.6 \\
$10 \sim 15$ & 2.931 & 0.22 & 15.3 & 5.4 \\
\hline
\end{tabular}

Table 3. Mix proportions of the EJR.

\begin{tabular}{lcccccc}
\hline Materials & $\begin{array}{c}\text { Fine aggregate } \\
0 \sim 3 \mathrm{~mm}\end{array}$ & \multicolumn{3}{c}{ Coarse aggregate } & \multicolumn{3}{c}{ Mineral powder } & Epoxy \\
\cline { 3 - 5 } & $3 \sim 5 \mathrm{~mm}$ & $5 \sim 10 \mathrm{~mm}$ & $10 \sim 15 \mathrm{~mm}$ & & \\
\hline Mix proportion & 1.56 & 1.41 & 2.26 & 1.88 & 0.702 & 0.624 \\
\hline
\end{tabular}


CHen W., Zheng Y, Tang CH., Zhuge W., Xu Y.

Preparation of the specimens

\section{Preparation of the EJR specimen}

A portable electric mixer was used to evenly mix the coarse aggregate, and then the mineral powder, sand and epoxy were evenly mixed and added to the mixed coarse aggregate. After mixing evenly, the prepared mixture was put into a mould all at once and vibrated for $30 \mathrm{~s}$. After curing in a fog room $\left(20 \pm 2{ }^{\circ} \mathrm{C}, 95 \%\right.$ relative humidity $(\mathrm{RH})$ ) for $18 \mathrm{~h}$, the prepared specimens were demoulded, as shown in Figure 2. The mechanical properties are shown in Table 4, which can meet traffic requirements.

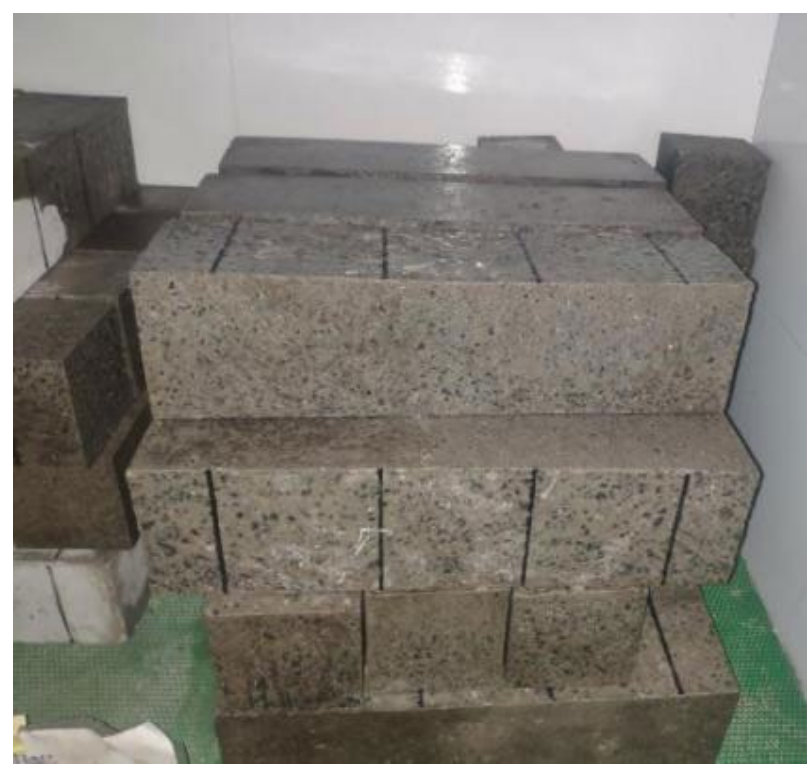

Figure 2. Preparation of the EJR specimens

Table 4. EJR mechanical performance indicators.

\begin{tabular}{lccccc}
\hline \multicolumn{2}{c}{ Compressive strength $(\mathrm{MPa})$} & \multicolumn{4}{c}{ Flexural strength $(\mathrm{MPa})$} \\
\hline $1 \mathrm{~d}$ & $28 \mathrm{~d}$ & $90 \mathrm{~d}$ & $1 \mathrm{~d}$ & $28 \mathrm{~d}$ & $90 \mathrm{~d}$ \\
45.2 & 92.4 & 109.1 & 4.2 & 16.1 & 21.2 \\
\hline
\end{tabular}

\section{Preparation of the concrete members} repaired by the EJR

The concrete specimen to be repaired (damaged concrete) was prepared by splitting the $100 \times 100 \times 400$ $\mathrm{mm}$ concrete specimens into half. The damaged concrete specimen was washed using a high-pressure water gun, and the sand filling depth of the repaired surface of each specimen was controlled to approximately $14 \mathrm{~mm}$. After the damaged concrete specimen was dried, it was put into the mould and injected with EJR. The concrete members repaired by EJR are shown in Figure 3.

\section{Fatigue testing method}

The fatigue test adopts the stress control mode, considering that the stress level of the pavement concrete ranges from 0.2 to 0.65 under the condition of no overload and from 0.55 to 0.85 under the condition of overload [18]. The stress ratio considers the pavement temperature stress to ensure that the specimen is not in a state of zero stress during each cycle. The loading frequency is $5 \mathrm{~Hz}$, which is equivalent to a vehicle speed of $60 \mathrm{~km} \cdot \mathrm{h}^{-1}$ [19]. The adopted fatigue testing parameters are shown in Table 5.

Table 5. Fatigue testing parameters

\begin{tabular}{lccc}
\hline $\begin{array}{l}\text { Stress } \\
\text { level }\end{array}$ & $\begin{array}{c}\text { Number } \\
\text { of specimens }\end{array}$ & $\begin{array}{c}\text { Frequency } \\
(\mathrm{Hz})\end{array}$ & $\begin{array}{c}\text { Stress } \\
\text { ratio }\end{array}$ \\
\hline 0.6 & 4 & 5 & 0.08 \\
0.7 & 4 & 5 & 0.08 \\
0.8 & 4 & 5 & 0.08 \\
0.9 & 4 & 5 & 0.08 \\
\hline
\end{tabular}

The midpoint bending fatigue test of the EJR and repaired concrete members is carried out with a 25 -tonne fatigue testing machine, as shown in Figure 4. The test mode adopts a stress control, and the criterion of the fatigue damage is the complete fracture of the specimen. The loading waveform is sinusoidal, and the loading frequency is $5 \mathrm{~Hz}$. Before fatigue testing, a three-point static loading test was carried out to obtain the failure load of the specimen, and then the stress mean value and amplitude of the fatigue test were calculated according to the stress level and stress ratio.

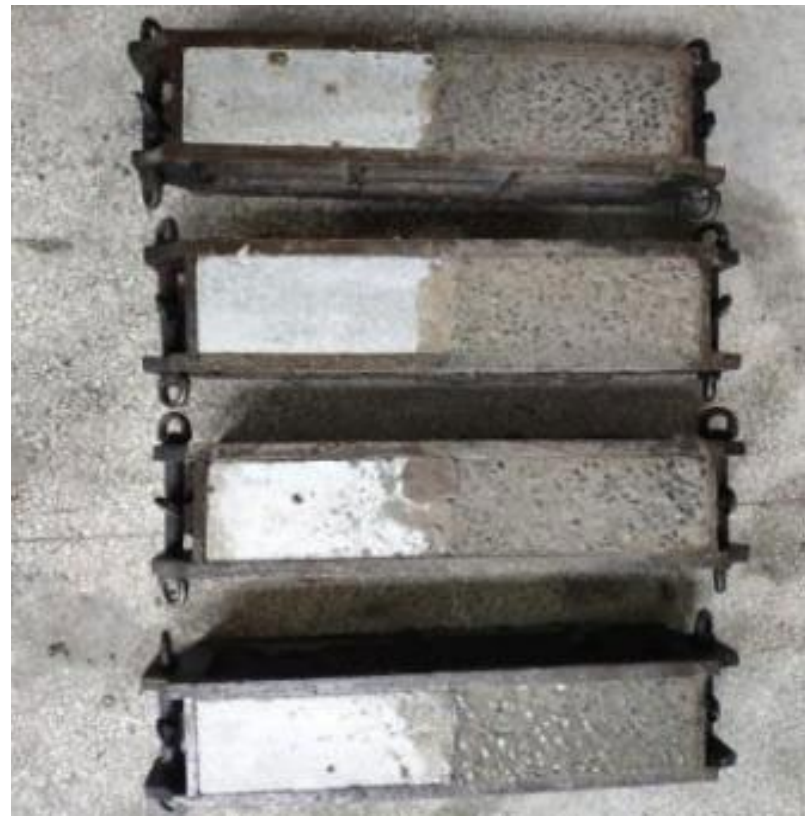

Figure 3. Preparation of the concrete members repaired by the EJR. 


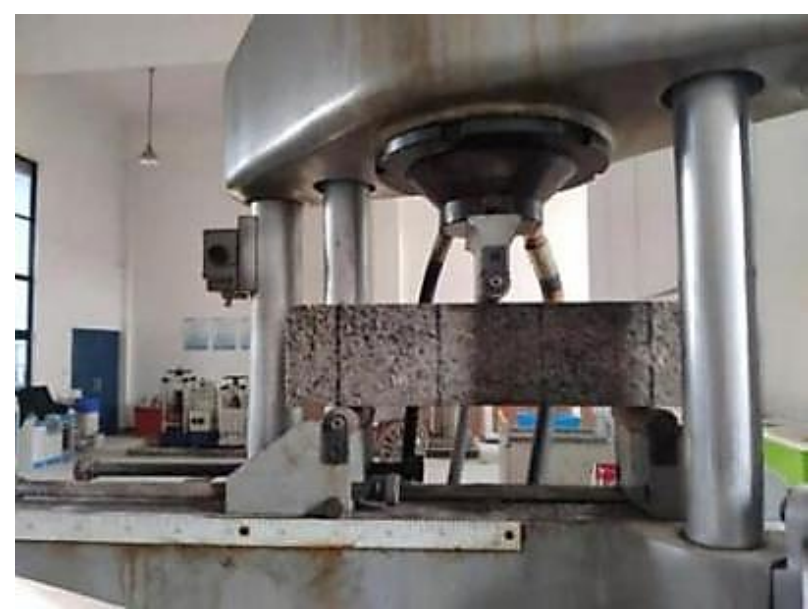

a) Static loading

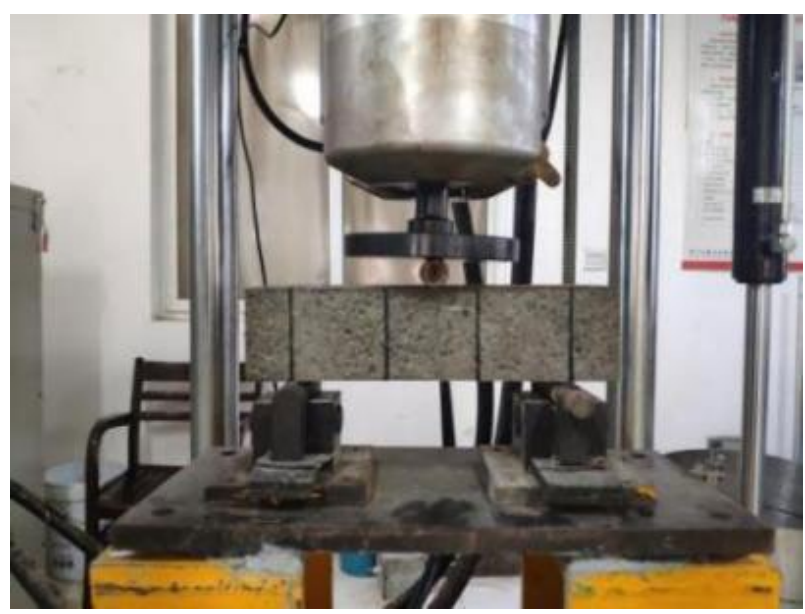

c) Fatigue loading of the EJR specimen

Figure 4. Loading methods.

\section{RESULTS AND DISCUSSION}

Fatigue performance of the EJR

Table 6 shows the fatigue testing results of the EJR specimens. When the fatigue failure of the EJR specimen occurs, the fracture surface generally appears in the middle of the specimen. When the stress level reaches 0.8 or above, the sound of a brittle fracture can be obviously heard. However, when the stress level is lower than 0.8 , the fracture sound of the specimen is softer, and the strength of the specimen is fully utilised, which indicates a ductile failure, as shown in Figure 5.

Table 6. Fatigue testing results.

\begin{tabular}{lc}
\hline Stress level $(S)$ & Fatigue life $\left(N_{f}\right)$ \\
\hline 0.6 & $1.0670 \times 10^{6}$ \\
0.7 & $1.3410 \times 10^{5}$ \\
0.8 & $1.1437 \times 10^{4}$ \\
0.9 & $1.0160 \times 10^{3}$ \\
\hline
\end{tabular}

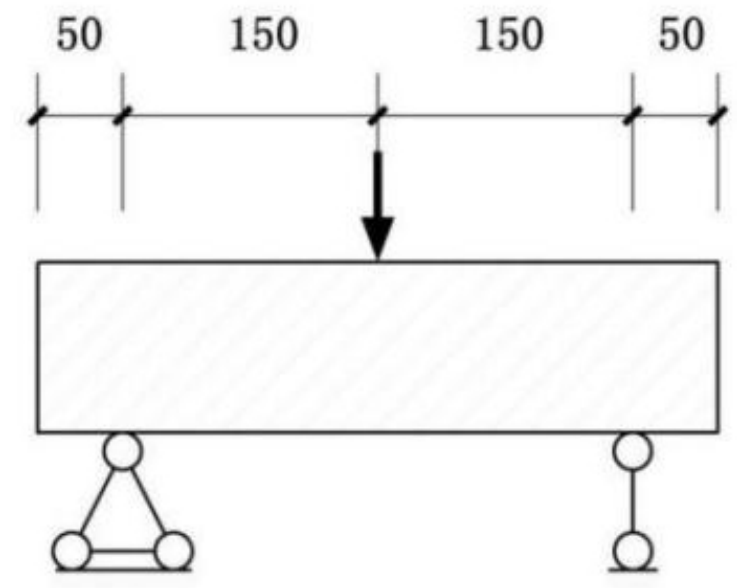

b) Schematic diagram of the static loading

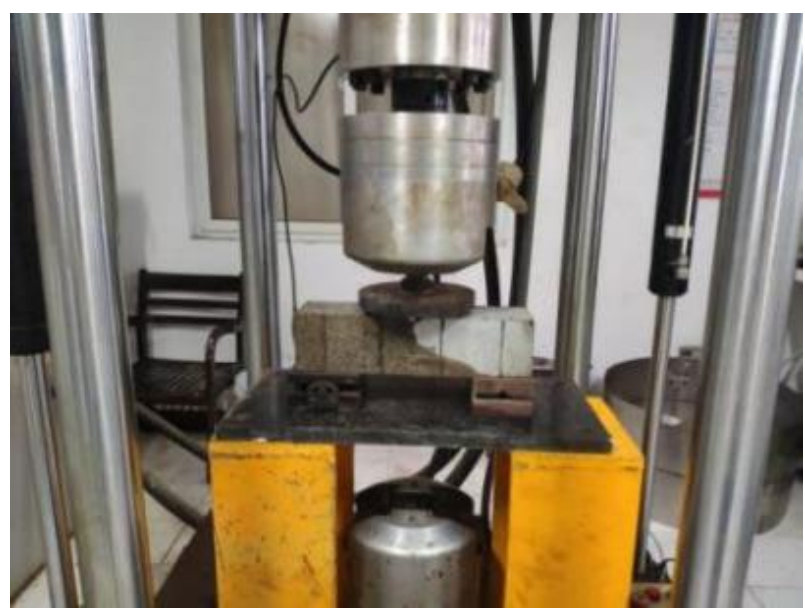

d) Fatigue loading of the repaired concrete member

\section{Phenomenological method}

The fatigue testing results of cement-based repair materials obtained by Li [20] and EJR are plotted in Figure 6. The results show that the fatigue life of the EJR specimen is higher than that of the cement concrete at the same stress level. With an increasing stress level, the fatigue life of the EJR and cement-based repair materials decrease significantly. There is a good linear relationship between the logarithmic fatigue life and the stress level, and the correlation coefficient of linear fitting can reach more than 0.99 . The corresponding fatigue life equations are established as follows:

EJR:

$$
\log N_{f}=-10.182 S+12.187
$$

Cement-based repair materials:

$$
\log N_{f}=-10.859 S+12.011
$$

where $N_{f}$ is the fatigue life; $S$ is the stress level. 


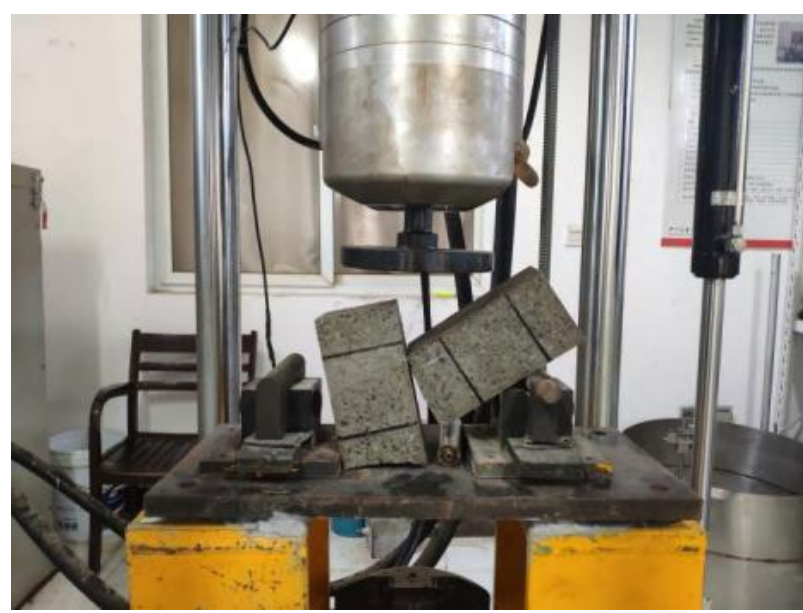

Figure 5. Fatigue failure of the EJR specimen.

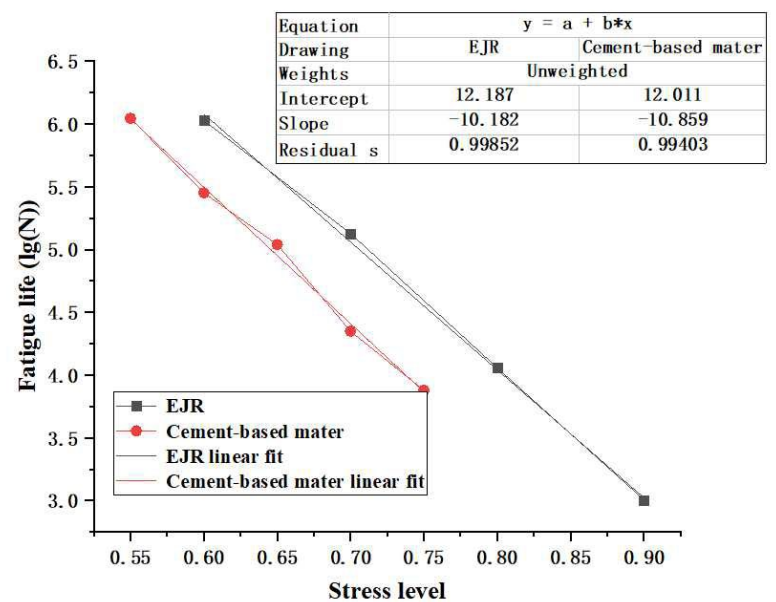

Figure 6. Logarithmic fatigue life of the cement-based repair materials and EJR.

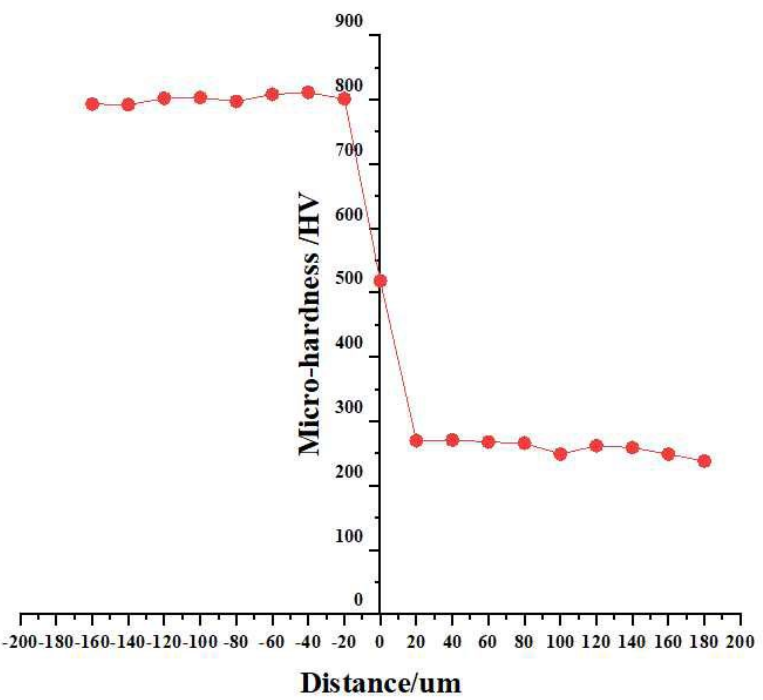

a) EJR
Comparing the two fatigue life equations, it can be seen that the slope of Equation 2 is higher than that of Equation 1 , while the intercept is smaller, which indicates that the fatigue life of the cement concrete is relatively sensitive to the change in stress, and the fatigue life of the cementbased repair materials is also lower than that of the EJR at a low stress level. Therefore, the fatigue performance of the EJR is better than that of the cement-based repair materials.

There is usually an obvious interface transition zone (ITZ) in the cement-based materials. However, the microhardness test results show that there is no interface transition zone in the EJR, as shown in Figure 7, which means that the EJR has fewer internal defects, thus strengthening the fatigue performance of the EJR.

\section{Energy method}

The existing research shows that the relationship between the total energy loss and the fatigue life of asphalt mixtures caused by fatigue failure has nothing to do with the testing methods and testing conditions, and there is a unique corresponding relationship between the total energy consumption resulting in the fatigue failure and fatigue life [22], as shown in Equation 3.

$$
W_{f}=A \cdot N_{f}^{B}
$$

where $W_{f}$ is the total energy consumption; $N_{f}$ is the fatigue life; and $A$ and $B$ are the material parameters determined by the experiment.

The total energy consumption $W_{f}$ is the sum of the hysteretic area of the stress-strain curve in the whole fatigue test process, which can be obtained by the integration method [23], as shown in Figure 8 and Figure 9, and the calculation results are shown in Table 7 . The results show that the strain increases with the increasing cyclic loading times. The smaller the stress

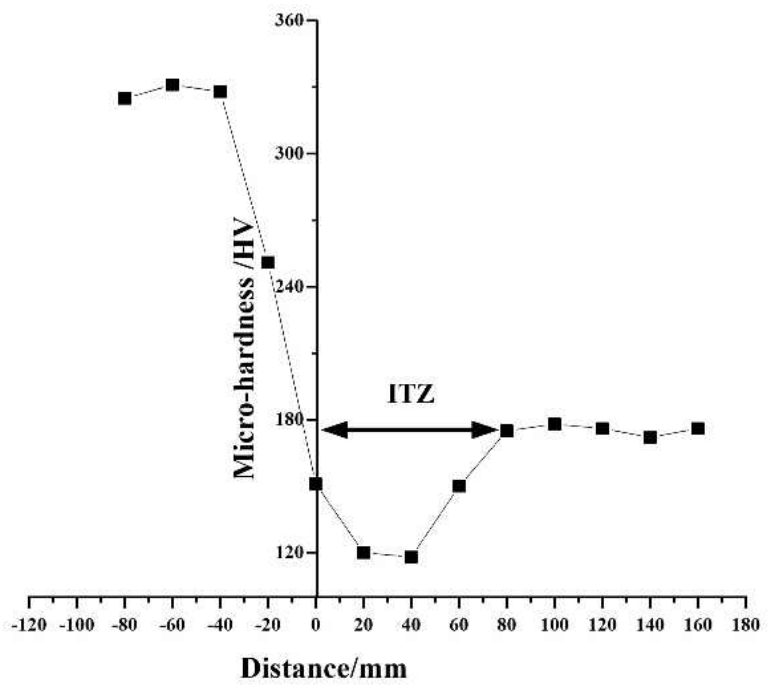

b) Cement-based materials [21]

Figure 7. Microhardness tests. 
level is, the greater the cumulative energy consumption is. There is a good linear relationship between the fatigue life and the cumulative total energy consumption in the double logarithm coordinate diagram. The correlation coefficient of the linear fitting can reach more than 0.98 . There is a unique corresponding relationship between the cumulative energy consumption and the fatigue life of the EJR. The fatigue equation established is as follows:

$$
\begin{aligned}
\log \left(W_{f}\right) & =0.227 \operatorname{g}\left(N_{f}\right)+3.427 \\
W_{f} & =2630.268 N_{f}^{0.228} .
\end{aligned}
$$

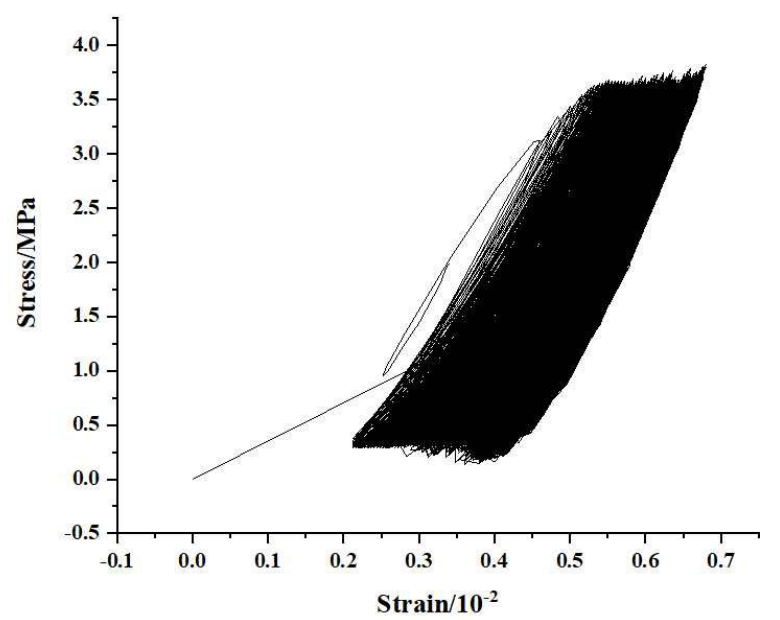

Figure 8. Fatigue stress-strain curve.

Table 7. Calculation results of the EJR energy consumption.

\begin{tabular}{lc}
\hline $\begin{array}{c}\text { Fatigue life } \\
(\mathrm{S})\end{array}$ & $\begin{array}{c}\text { Cumulative energy } \\
\text { consumption }(\mathrm{MPa})\end{array}$ \\
\hline $1.0670 \times 10^{6}$ & 60009.9 \\
$1.3410 \times 10^{5}$ & 39069.3 \\
$1.1437 \times 10^{4}$ & 25255.9 \\
$1.0160 \times 10^{3}$ & 11892.5 \\
\hline
\end{tabular}

Fatigue performance of the repaired concrete members

Table 8 shows the fatigue testing results of the concrete members repaired by EJR under different stress levels. When the fatigue failure of the concrete members occurs, the failure surface occurs in the damaged concrete, indicating that EJR has good bonding performance, as shown in Figure 10.

Table 8. Fatigue life of the concrete members repaired by EJR.

\begin{tabular}{cc}
\hline Stress level $(\mathrm{S})$ & Fatigue life $\left(\mathrm{N}_{\mathrm{f}}\right)$ \\
\hline 0.6 & $1.062 \times 10^{6}$ \\
0.7 & $1.967 \times 10^{5}$ \\
0.8 & 1311 \\
0.9 & 30
\end{tabular}

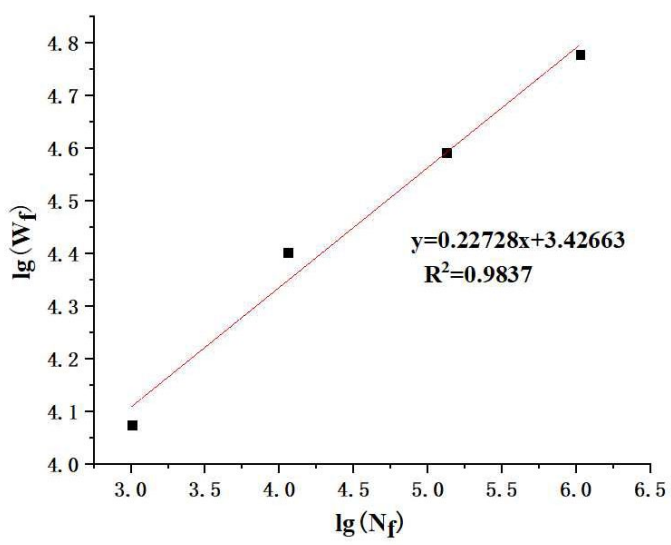

Figure 9. Relationship between the fatigue life and the cumulative energy consumption.

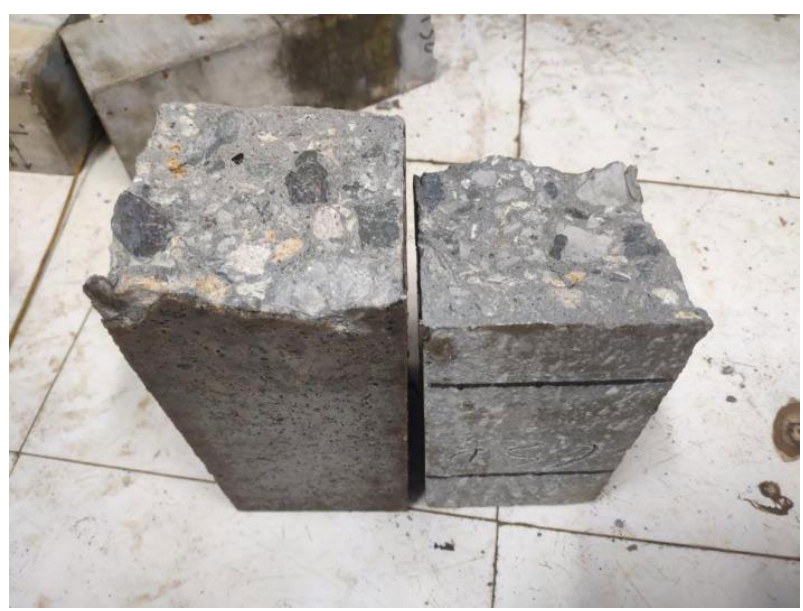

Figure 10. Fatigue damage of the concrete members repaired by EJR.

\section{Phenomenological method}

The fatigue testing results of the concrete members repaired by the cement-based materials obtained by Yan [24] and the concrete members repaired by EJR are plotted in Figure 11. The results show that the fatigue life

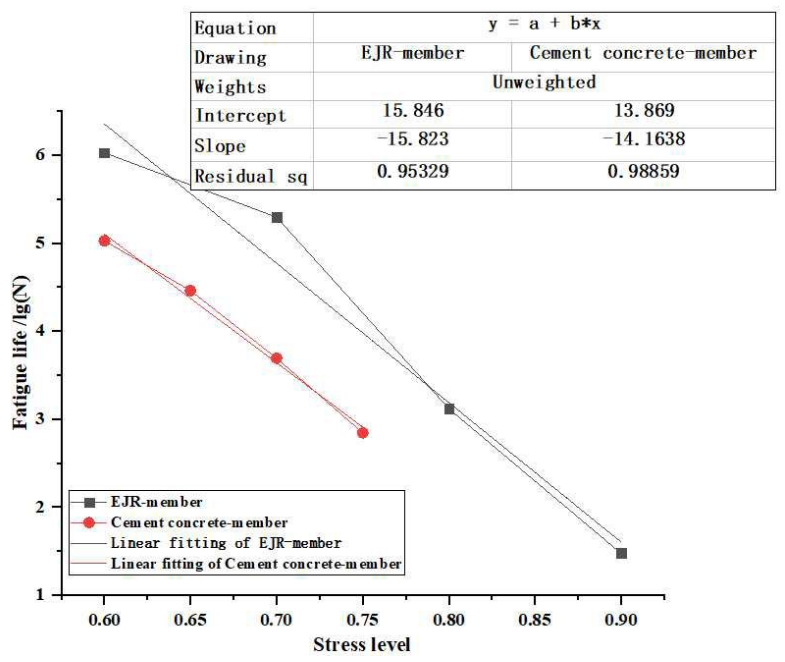

Figure 11. Fatigue life curve of the repaired concrete members. 
of the concrete members repaired by EJR is higher than that of the concrete members repaired by the cementbased materials at the same stress level. The regression analysis shows that there is a good linear relationship between the logarithmic fatigue life and the stress level of the two kinds of repaired concrete members, and the regression coefficient of the fitting results can reach more than 0.95 . The established fatigue life equations are shown in Equation 6 and Equation 7. By comparing the two equations, it can be found that the slope and intercept of the former are much larger than those of the latter, indicating that the sensitivity of the concrete members repaired by EJR to stress is greater than that of the concrete members repaired by the cement-based materials. Compared with cement-based repair materials, EJR has better bonding properties and lower shrinkage. Therefore, the fatigue performance of the concrete members repaired by EJR is better than that of the concrete members repaired by cement-based materials.

Concrete members repaired by EJR:

$$
\log \left(N_{f}\right)=-15.823 S+15.846
$$

Concrete members repaired by cement-based materials:

$$
\log \left(N_{f}\right)=-14.614 S+13.870
$$

\section{Energy method}

Table 9 shows the total energy consumption of the fatigue failure of concrete members repaired by EJR, and the calculation results are fitted by Equation 3. The results show that the cumulative energy consumption and fatigue life show a good linear relationship in the double logarithmic coordinate system, and the correlation coefficient can reach more than 0.98 , as shown in Figure 12.

$$
\begin{aligned}
\log \left(W_{f}\right) & =0.344 g\left(N_{f}\right)+2.268 \\
W_{f} & =185.353 N_{f}^{0.344}
\end{aligned}
$$

Table 9. Energy consumption of the concrete members repaired by EJR.

\begin{tabular}{cc}
\hline Stress level (S) & Energy consumption (MPa) \\
\hline 0.6 & 27453.2 \\
0.7 & 8944.8 \\
0.8 & 2397.4 \\
0.9 & 591.3 \\
\hline
\end{tabular}

\section{CONCLUSION}

(1) The fatigue performance of the EJR and repaired concrete members were analysed using phenomenological methods, and it was found that the fatigue life equations of both are suitable in semilogarithmic form, and the correlation coefficients of linear fitting are above 0.95 .

(2) Based on the theory of energy consumption, the total energy consumption of the specimens is

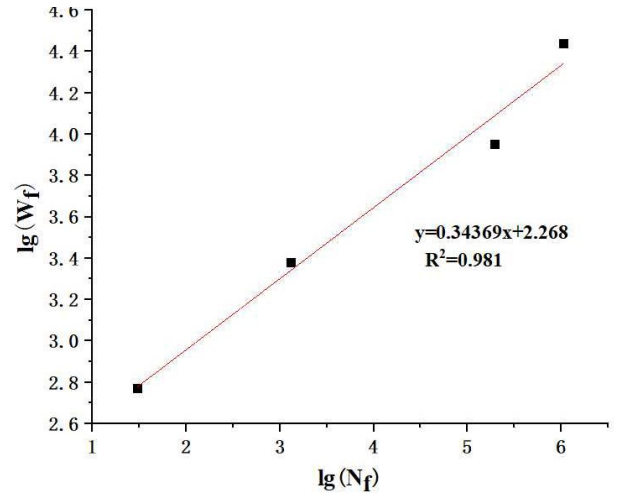

Figure 12. The relationship between the fatigue life and the cumulative energy consumption.

obtained. The results show that there is a good linear relationship between the fatigue life and the cumulative total energy consumption of both the EJR and repaired concrete members in double logarithmic coordinates.

(3) EJR has excellent fatigue performance. The fatigue performance of the concrete members repaired by EJR is better than that of the concrete members repaired by cement-based materials.

(4) For a better comparison, the fatigue performance of cement concrete and cement-based repair materials can be investigated in the future.

\section{Acknowledgment}

The authors wish to acknowledge the financial support of the "Ningbo traffic science and technology project (Grant No. 201903)" and the Zhejiang Construction Research Project (Grant No. 2020K063).

\section{REFERENCES}

1. Zheng Z., Li Y., He S., Ma X., Zhu X., Li S. (2019): High density and high strength cement-based mortar by modification with epoxy resin emulsion. Construction and Building Materials, 197, 319-330. doi:10.1016/ /j.conbuildmat.2018.11.167

2. Baldissera A. F., Schütz M. K., Vecchia F. D., Seferin M., Ligabue R., Menezes S. C., Einloft S. (2017): Epoxy-modified Portland Cement: Effect of the Resin Hardener on the Chemical Degradation by Carbon Dioxide. Energy Procedia, 114, 5256-5265. doi: 10.1016/j.egypro.2017.03.1682

3. Guo W. (2009): Research on the optimal formulation of epoxy resin-based repaire material. New Building Materials, 36, (08), 58-62.

4. Lei Y., Jiang M., Chen H., Zhang L. (2013): Mechanical Performance of Repair Materials for Epoxy Resin Concrete Pavement Cured by Microwave. Journal of Building Materials, 16, (04), 599-602. doi:10.3969/j.issn.1007$-9629.2013 .04 .008$

5. Zhang P., Li Y., Xu M. (2009): Experimental study on flexural deformation behavior of epoxy resin concrete. Journal of China \& Foreign Highway, 29, (01), 208-211.

6. Liu K. (2010): Study on fatigue performance of epoxy resin 
concrete. Journal of China \& Foreign Highway, 30, (05), 297-300.

7. Chen T., Qian Z. (2012): Research on the Fatigue Property of Multilayered Pavement on Concrete Bridge Deck. Journal of Wuhan University of Technology (Transportation Science \& Engineering), 36, (02), 319-323. doi: 10.3963/ j.issn.1006-2823.2012.02.024

8. Shafabakhsh G. H., Ani O. J. (2015): Experimental investigation of effect of Nano $\mathrm{TiO} 2 / \mathrm{SiO} 2$ modified bitumen on the rutting and fatigue performance of asphalt mixtures containing steel slag aggregates. Construction and Building Materials, 98, 692-702. doi: 10.1016/ j.conbuildmat.2015.08.083

9. Lv S., Liu C., Qu F., Zheng J. (2020): Test Methods and Characterization of Fatigue Performance of Asphalt Mixtures: A Review. China Journal of Highway and Transport, 33, (10), 67-75. doi: 10.3969/j.issn.1001$-7372.2020 .10 .002$

10. Mannan U. A., Islam M. R., Tarefder R. A. (2015): Effects of recycled asphalt pavements on the fatigue life of asphalt under different strain levels and loading frequencies. International Journal of Fatigue, 78, 72-80. doi: 10.1016/ j.ijfatigue.2015.04.004

11. Liu W., Rong, H. (2011): Study on Fatigue Properties of Structural Concrete in China. Materials Review, 25, (19), 134-142.

12. Ding Z., Li J. (2015): Summary of fatigue analysis methods of concrete. Mechanics in Engineering, 37, (01), 40-48. doi: 10.6052/1000-0879-14-167

13. Yang L., Hou S. (2017): Study on Fatigue Residual Life of Reinforced Concrete Beam Bridge Based on Dissipated Energy Density. Highway Engineering, 42, (03), 231-234. doi:10.3969/j.issn.1674-0610.2017.03.047

14. Zhang H., Qian J., Wu W., Zhang F., Hao Z. (2010): Fatigue Life Analysis of Gussasphalt Concrete Based on Energy Method. Journal of Civil and Environmental Engineering, 32, (04), 135-140. doi: 10.11835/j.issn.16744764.2010.04.026

15. Ameri M., Mansourkhaki A., Daryaee D. (2019): Evaluation of fatigue behavior of asphalt binders containing reclaimed asphalt binder using simplified viscoelastic continuum damage approach. Construction and Building Materials, 202, 374-386. doi: 10.1016/j.conbuildmat.2019.01.021

16. Wang J., Qian Z., Chen L., Peng G. (2013): Fatigue Property of Composite Deck Pavement of Cement Concrete Bridge Based on Energy Consumption Method. Journal of Highway and Transportation Research and Development, 30, (09), 74-79. doi: 10.3969/j.issn.1002-0268.2013.09.012

17. Zhang Q., Wang L. (2020): Fatigue crack propagation model of concrete under water pressure based on energy approach. Hydro-Science and Engineering, (03), 106-113.

18. Guo Y., Shen A., Tian F., Zhou S. (2017): Mechanical Property of Pavement Cement Concrete Under Dynamic Fatigue Load. China Journal of Highway and Transport, 30, (07), 18-24. doi: 10.3969/j.issn.1001-7372.2017.07.003

19. Huang W., Yu J., Zhang X. (2007): Study on Steel Deck Pavement Fatigue Performance. Highway Engineering, (04), 37-39. doi: 10.3969/j.issn.1674-0610.2007.04.009

20. Li B., Yin L., Fan L. (2017): Analysis on Flexural Fatigue Performance of Manufactured Sand Concrete. Journal of Building Materials, 20, (05), 801-807. doi: 10.3969/ j.issn.1007-9629.2017.05.024

21. Dong Y., Yang H., Zhang L., Lin Y. (2014): Effects of Aggregate Interface Characteristics on the Mechanical Property of Concrete. Journal of Building Materials, 17, (04), 598-605. doi: 10.3969/j.issn.1007-9629.2014.04.007

22. Yang G., Wang X., Shi J. (2018): Evaluation of Anti-fatigue Characteristic of Hard Asphalt Mixture Based on Dissipated Energy Method. Journal of Building Materials, 21, (06), 913-919. doi: 10.3969/j.issn.1007-9629.2018.06.009

23. Tian X., Lv S., Zheng J. (2005): Bituminous Mixture Fatigue Effect Study. Journal of Highway and Transportation Research and Development, (10), 11-13. doi: 10.3969/ j.issn.1002-0268.2005.10.004

24. Yan Z. (2014). Research on high performance repair materials and application technology based on thin layer disease of concrete pavement. Chang'An University 